\title{
Possible Antipsychotic Effect of Fluvoxamine
}

To the Editor:

May 11, 2005

I am responding to the article by Dr. Stephen Stahl entitled "Antipsychotic treatment of psychotic major depression: potential role of the $\sigma$ receptor" (CNS Spectr. 2005;10(4):319-323). ${ }^{1}$ The following case report seems to illustrate the role of fluvoxamine as an antipsychotic, thus supporting Dr. Stahl's hypothesis.

\section{BACKGROUND}

Fluvoxamine has traditionally been considered an antidepressant which works well both to treat obsessive-compulsive disorder and for depressive disorders. However, there has been some recent speculation about using it as an antipsychotic, either as monotherapy or as an augmenting agent. A brief report by Levkovitz and colleagues ${ }^{2}$ discussed a small study in which low-dose fluvoxemine was used to augment perphenazine in psychotic Alzheimer's patients, with good antipsychotic effect. More recently, Stahl ${ }^{1}$ proposed that the selective serotonin reuptake inhibitor (SSRI) $\sigma$ receptor may be responsible for previously unknown antipsychotic effects and he cited several studies involving SSRI monotherapy efficacy for major depression with psychosis. The following case seems to support the evidence that fluvoxamine in particular may exert an effect on psychosis.

\section{CASE PRESENTATION}

A 53-year-old African American female with a history of schizoaffective disorder was taking risperidone and fluvoxamine for 5 years with good effect, but had some chronic baseline auditory hallucinations. The decision was made to start her on risperidone long-acting injection in February 2004 , and over the course of the next 6 months, her dose of risperidone long-acting injection was titrated up to $50 \mathrm{mg}$ every 2 weeks and oral risperidone was discontinued. Her auditory hallucinations stopped and the patient remained symptom free. In December 2004, she self-discontinued fluvoxamine due to possible cognitive side effects. In January 2005, escitalopram was begun for increasing depressive symptoms. No dosage change was made in her risperidone long-acting injection. Her depression improved but she began experiencing auditory hallucinations again in March.
Despite the addition of oral risperidone, the patient continued to experience hallucinations until fluvoxamine was restarted in late March, at which point her psychosis began to improve. However, she self-discontinued the fluvoxamine in mid-April, after which she began experiencing auditory hallucinations and delusions once more, decompensating until she required psychiatric hospitalization at the end of the month. Fluvoxamine was restarted with no other medication additions or changes, and currently her hallucinations are much decreased and continuing to improve.

\section{CONCLUSION}

Although this patient did not do well while taking escitalopram, she began to recover once fluvoxamine was restarted. Since there were no other medication changes that could account for her reduction in symptoms, it is likely that fluvoxamine has had a role in the past in maintaining her stability and has acted more recently to reduce her positive symptoms of schizophrenia. This case seems to support the interesting new hypothesis that fluvoxamine may be useful in controlling psychotic symptoms.

Sincerely,

Sara Goldman, MD

Cleveland, $\mathrm{OH}$

\section{REFERENCES}

1. Stahl SM. Antidepressant treatment of psychotic major depression: potential rule of the o receptor. CNS Spectr. 2005;10:319-323.

2. Levkovitz Y, Bloch Y, Kaplan D, Diskin A, Ahramovitchi 1. Flusoxamine for psychosis in Alzheimer's disease. J Nert Ment Dis. 2001:189:126-129.

Dr. Goldman is staff psychiatrist in the Department of Behavioral Health at the Center for Families and Children in Cleveland, Ohio.

Disclosure: Dr. Goldman does not have an affiliation with or financial interest in any organization that might pose a conflict of interest.

\section{DR. STAHL'S RESPONSE}

The above case report by Goldman illustrates how a sophisticated and observant clinician can apply a theoretical mechanism of action concept to find a unique therapeutic solution for an individual patient. By conducting a simple A-B-A open-label design in a single patient, Goldman found an apparent antipsychotic action of fluvoxamine but not of escitalopram in her patient. These observations are consistent with the 


\section{Letter to the Editor}

notion that fluwoxamine may have unique antipsychotic actions due to its $\sigma$ binding properties. ${ }^{1}$

On one hand, all serotonin selective reuptake inhibitors (SSRIs), including fluvoxamine, escitalopram, and several others, should have identical therapeutic actions because they all have the primary action of being selective blockers of the serotonin transporter. ${ }^{2}$ Such an action would be expected to be antidepressant and anxiolytic but not necessarily antipsychotic.

On the other hand, it is a universal experience among active clinicians that patients who do not respond to one SSRI not infrequently will respond to another, or patients who do not tolerate one SSRI will tolerate another. ${ }^{3}$ The major hypothesis to explain the differences among SSRIs is that their secondary binding properties, which are all different from each other, may account for the clinical differences observed. ${ }^{2-4}$ Well-informed clinicians are aware of the theoretical differences among drugs of the SSRI class, and try to exploit these to match the very best treatment to the individual patient, just as Goldman cleverly did for her patient. Because cases like she describes with unique benefits and reactions to individual agents within a therapeutic class are not rare, it is best for formulary committees to allow open access to all agents in this class so that clinicians have access to all the tools to best treat their patients. ${ }^{5}$

This concept of individual differences observed for patients is also seen with the atypical antipsychotics, and for perhaps the same general reason..$^{5-7}$ That is, all atypical antipsychotics are antagonists of serotonin $5-\mathrm{HT}_{2 \mathrm{~A}}$ and dopamine $D_{2}$ receptors, but they also have very different secondary binding properties that are the leading hypothesis to explain the differences in efficacy and tolerability observed for drugs in this class as well..$^{6,7}$

The bottom line is that clinicians would do well to familiarize themselves not only with the pharmacologic characteristics that are common to drugs in a given therapeutic class but also the individual distinctions between drugs within these classes. Formulary committees would be well advised to keep open access to therapeutic classes of drugs, such as SSRIs and atypical antipsychotics, so that individual patients can receive optimized therapeutic benefits. ${ }^{5}$ With this information about hypothetical mechanism of action in mind, clinicians may be better able to explain differences in reactions to individual drugs by unique patients, and with this explanation, be able to exploit these differences to find the best therapeutic benefit for each patient, just as Goldman has done.

Sincerely,

Stephen Stahl, MD, PhD

\section{REFERENCES}

1. Stahl SM. Antidepressant treatment of major depression: potential role of the 0 receptor. CNS Spectr 2005; 10:319-323.

2. Stahl SM. Not so selective serotonin reuptake inhihitors. I Clin Psychiatry. $1998 ; 59: 343-344$.

3. Stahl SM. Using secondary binding properties to select a not so selective serotonin reuptake inhibitor. J Clin Psychiatry. 1998;59:642-643.

4. Staht SM. Selectivity of SSRIs: individualizing patient care through rational treatment choices. Int J Psy Clin Prac. 2004:8(suppl 1):3-10.

5. Stahl SM. Let them eat generics: can one atypical antipsychotic substitute for another? PsychEd Up. 2005;1:6-7.

6. Stahl SM, Shayegan DK. The psychopharmacology of ziprasidone: receptor-hinding propertics and teal-world psychiatric practice. J Clin Psychiary. 2003;64(suppl 19):6-12.

7. Shayegan DK, Stahl SM. Atypical antipsychotics: matching receptor profile to individual patient's clinical profile. CNS Spectr. 2004:9(suppl 11):6-14.

Please send letters to the editor to: CNS Spectrums, clo Jack M. Gorman, MD, 333 Hudson St., 7th Floor, New York, NY 10013; E-mail: sb@mblcommunications.com

\section{ERRATUM}

In the August From the Editor's Desk, "Sad Seasons: Winter Mood Not Always Holiday Blues" (CNS Spectr. $2005 ; 10(8): 605)$, The New York Times article by Friedman RA, "Behavior; a Blue Holiday May Be a Red Herring" (December 16, 2005: F5) was incorrectly cited as a reference. Dr. Friedman's article correctly noted seasonal affective disorder to be a valid, treatable psychiatric illness. We regret the error. 